\title{
A Integração Acadêmica do Refugiado Estudante ${ }^{1}$
}

\author{
Carolina Miranda Futuro ${ }^{2}$
}

\section{Resumo}

O presente trabalho visa analisar os múltiplos fatores envolvidos na integração acadêmica de um refugiado em um sistema de ensino superior. Devido à sua condição particular, o refugiado que se encontra na universidade enfrenta algumas barreiras agudas frente a sua integração acadêmica e social dentro do espaço universitário, que é essencial para a conclusão do ensino. Dessa forma, fatores como a adaptação linguística, o apoio financeiro, a adaptação cultural, entre outros, devem receber atenção especial. Portanto, o artigo tem como principal objetivo apontar tais variáveis que carecem de maior atenção em casos de refúgio e analisar se medidas estão sendo tomadas por atores brasileiros para que se assegure a efetiva integração de refugiados que foram admitidos em universidades. Tomando como base algumas variáveis destacadas na Escala de Integração Acadêmica (ISA), são verificadas iniciativas presentes no Brasil para a diminuição das barreiras de refugiados frente a sua integração na faculdade.

Palavras-chaves: Refúgio, Educação Superior, Integração.

\section{Abstract}

The paper aims to analyze multiple variables that affect the academic integration of refugees in higher education systems. Due to their particular situation, refugees that find themselves inside foreign universities, also face certain barriers that stand in their way to a complete social and academic integration inside the university, which is essential to the conclusion of the education process. In this sense, factors such as linguistic adaptation, financial support, cultural integration, amongst others, require special attention. Therefore, this article aims to point out the variables that stand in the way of integration, therefore, it deserve special attention in cases of refugee students, and analyze wether actions are being taken by Brazilian actors in order to secure an effective integration in this scenario. Taking as a starting point the Academic Integration Scale (ISA), the paper will verify if there are Brazilian initiatives to help reduce barriers and therefore facilitate integration in universities.

Key words: Refugees, Tertiary Education, Integration.

\section{Introdução}

A prática de refúgio, uma vez que se apresenta como uma ação humanitária que propõe receber pessoas que precisam se mover pois se sentem perseguidas em seus países natais (ONU, 1951), deve ser sempre pensada no sentido do acolhimento amplo. Para que esse seja efetuado, é preciso que uma gama de ações sejam tomadas para que o refugiado seja integrado

\footnotetext{
${ }^{1}$ Este artigo é resultado do Programa de Educação Tutorial do Instituto de Relações Internacionais da Pontifícia Universidade Católica do Rio de Janeiro (PET-TEPP/PUC-Rio).

${ }^{2}$ Graduanda em Relações Internacionais pelo Instituto de Relações Internacionais da Pontifícia Universidade Católica do Rio de Janeiro (IRI-PUC-RIO). E-mail: carolina.m.futuro@gmail.com.
} 
efetivamente em sua nova sociedade e consiga participar ativamente em seu novo local. No entanto, na prática, nem sempre essa integração essencial ocorre, em parte por causa da pouca iniciativa da sociedade receptora de acomodá-los, como também por causa de uma intransigência de governos locais em adotarem certas medidas políticas que facilitariam essa integração (Azevedo et al, 2017). O reconhecimento das particularidades e necessidades específicas que refugiados, portanto, precisam ser mais bem abordadas na prática do refúgio. Um campo que representa um caminho potencial para a integração, mas que precisa ser melhor abordado por atores locais é a educação.

A educação, segundo as diretrizes do Direito Internacional, é um elemento essencial dentro dos Direitos Humanos e é sempre apontada por tratados internacionais sobre refúgio como um direito inegável (ACNUR, 2018). A própria convenção relativa ao Estatuto dos Refugiados (ONU, 1951), define que é um direito de todo refugiado a conclusão do ensino fundamental e médio, de modo que todo e qualquer Estado que aceita refugiados deve prover tais serviços às crianças. O mesmo, porém, não pode ser dito sobre a educação superior. Apesar das organizações internacionais como a ACNUR ou a ONU, ao mencionarem o poder emancipador e integrativo da educação, sempre se referirem à educação em todos os níveis, o acesso à educação superior não é tratada como direito essencial do refugiado. Ao invés disso, ela segue a lógica de legislações nacionais em que o acesso deve ser permitido de acordo com o mérito individual (ONU, 1951).

Essa prática, porém, ignora diversas barreiras que se colocam frente ao acesso especificamente do refugiado à universidade, como a barreira linguística, financeira, de revalidação de diplomas, entre outras. Nesse sentido, se olharmos para as estatísticas internacionais, somente $1 \%$ de refugiados no mundo ingressam em faculdades (ACNUR, 2018) criando, assim, múltiplas deficiências à situação de refugiados que não conseguem seguir para o ensino superior. Nesse seguimento, há a diminuição das chances já precárias da integração do refugiado no mercado de trabalho formal, e subsequentemente a diminuição de sua qualidade de vida e a criação de uma "geração perdida" ${ }^{3}$. Além disso, o não-acesso à educação superior pode significar um déficit frente a integração efetiva de alguns refugiados. Sendo assim, seria necessário o aumento do número de refugiados em universidades. Tal necessidade costuma ser reconhecida por meio de ações promovidas pelos Estados, universidades ou organizações que

\footnotetext{
${ }^{3}$ Estudos chamam atenção para casos extremos em que é possível a criação de uma massa de jovens de um país, que não ingressam na universidade, o que, em casos de crises duradouras e severas, como a da Síria, pode afetar a capacidade da população futura do país, ao final da crise, na reconstrução de seu Estado (Güney, 2017).
} 
procuram atenuar algumas das barreiras anteriormente mencionadas ao acesso do refugiado na universidade.

Ainda relevante, porém, é a questão da integração do refugiado uma vez dentro das universidades brasileiras. Isto é, é preciso, além do aumento de adesão de refugiados em universidades, que a eles também sejam oferecidas oportunidades de viver uma experiência acadêmica positiva e, assim, consigam se formar nos seus devidos cursos (Rientes et al, 2011). Nesse sentido, não compensaria ter uma taxa de ingresso crescente de refugiados em faculdades, mas uma alta taxa de evasão do ensino. Afinal, se este for o caso, temos um indicativo de que o objetivo da integração efetiva não ocorreu, e os possíveis benefícios de um ensino superior nesse cenário são perdidos.

Sendo assim, não é suficiente que se estude e crie condições somente para a entrada de refugiados em universidades. Ao invés disso, também é preciso que se olhe para a criação de condições para que refugiados consigam completar seu ensino. Ou seja, é preciso ainda fazer uma avaliação da promoção da integração acadêmica de refugiados, em nível social, cultural e financeiro para determinar se existem condições suficientes para que estes atinjam seu objetivo de concluir o ensino superior e conseguir ser integrado ao mercado de trabalho local.

No Brasil, o principal orgão que lida com a inserção de refugiados em universidades, é a inciativa da ACNUR chamada Cátedra Sérgio Vieira de Mello. A cátedra procura diminuir certas barreiras frente ao acesso de refugiados à universidade, ao oferecer, por exemplo, aulas de português para refugiados, assistência monetária e serviços de revalidação de diplomas (ACNUR Brasil, 2018). Resta saber, porém, que ações a organização promove para atender aos refugiados que já passaram pelo processo seletivo de entrada nas universidades, e se há outros orgãos se envolvem com o assunto.

Para que se avalie essas iniciativas, o artigo se concentrará primeiro em investigar teoricamente tópicos que tangenciam a problemática. Assim, a primeira seção da presente pesquisa, se volta para uma revisão bibliográfica sobre estudos que envolvem os temas da integração, do sistema de educação superior e de integração acadêmica, de modo a melhor entender as necessidades e especificidades do caso de adaptação de refugiados ao ensino superior. Em seguida, o artigo focará sua análise no caso brasileiro, assim, promovendo uma tentativa de mapear as iniciativas tomadas por orgãos nacionais ligados ao tema de refugiados ou ao ensino superior e tentativas de integração academica. 


\section{Análise teórica sobre integração acadêmica}

De acordo com Ola Mostafa (2017), o objetivo de qualquer processo de integração, seria alcançar uma harmonia de grupo (Mostafa, 2017, p. 17). Segundo o autor, apesar de não haver uma definição específica sobre o fenômeno da integração, esse ideal costuma sempre envolver uma noção de incorporação, ou do fim de uma separação. No quadro do refúgio, uma vez que esse é entendido conceitualmente como o movimento de acolhimento daqueles cujos Estados originários se provaram incapazes de protegê-los (Moreira, 2014), essa harmonia de grupo se torna extremamente importante sendo, inclusive, defendida por múltiplas convenções impulsionadas pela ONU (ACNUR, 2018). Nesse sentido, o refúgio é intrinsecamente ligado ao conceito do Estado, representando tanto a incapacidade de uma nação de performar seu papel de proteção dos seus cidadãos, tanto a habilidade de outra nação que se propõe a proteger os cidadãos de outro país e lhes conceder asilo, em nome dos Direitos Humanos (Moreira, 2014). Tal movimento, nesse sentido, é relacionado à busca da garantia de direitos e proteção de um Estado a um individuo.

Dessa forma, é preciso que o refugiado consiga prover-se desse vínculo com um novo Estado através da integração à sua nova sociedade. É aqui defendido então, que a incorporação de refugiados às suas novas sociedades, deve ser feita de maneira efetiva para que se consiga fazer possível a convivência entre diversas culturas e de fato proporcionar uma melhoria das condições de vida de refugiados, como se propõe o objetivo do movimento de acolhimento. É preciso, assim, que refugiados se integrem às suas novas sociedades, de forma a tornar viável a convivência conjunta com a população local (Kuhlman, 1991).

Em si, essa integração é multidimensional. Ou seja, temos tanto o elemento da integração pessoal e cultural de refugiados, o que implica a sua possibilidade e capacidade de estabelecer vínculos com a população local, como também a integração social, étnica, que implica a possibilidade dos refugiados de acesso a serviços básicos públicos, ou a aceitação no mercado de trabalho, aos seus direitos políticos, entre outros. É somente quando os refugiados se veem acolhidos em todos esses múltiplos aspectos - em que podem conseguir um emprego, tenham acesso a educação, a direitos políticos e sejam recebidos pela população local - que se pode dizer que os mesmos estão integrados, incluídos pelo sistema estatal (Moreira, 2014).

É ainda importante salientar que, como apontado por Mostafa (2017), o conceito de integração envolve ambos fatores internos como externos - é uma "via de mão-dupla" (Moreira, 2014, p.89). Isto é, é preciso que tanto o refugiado quanto a sociedade receptora trabalhem em conjunto para assegurar a convivência ideal. Porém, mais problemático é a tendência da 
população local de ver refugiados como estrangeiros, os que não pertencem à nação, à cultura local, de modo que há uma reticência em considerá-los como "nós", o que leva a não-integração e uma falta de pertencimento por parte dos refugiados (Moreira, 2014). Desse modo, Mostafa posiciona como uma condição necessária para a integração efetiva dos refugiados, o esforço ativo da população nacional, que, segundo ele, deve reconhecer as diferenças com os refugiados, e identificar as necessidades dessa minoria. Se destaca, portanto, o elemento da hospitalidade entre a população local, expressado na aceitação e recebimento do estrangeiro (Chueiri, 2010). Em uma linha de pensamento parecida, também se torna papel do Estado acolher oficialmente os refugiados, promover políticas que tenham como o objetivo a integração desses, bem como desencorajar a reticência da população local quanto a integração na sociedade, buscando diminuir a discriminação usual nesses cenários.

Entretanto, como apontado por Jacqueline Stevenson e Sally Baker (2018), na prática tais esforços costumam não costumam ser bem sucedidos. Em grande parte, isso pode ser atribuído aos efeitos dos discursos feitos ao redor da migração forçada que frequentemente associa o refúgio com a migração ilegal e com uma ideia de terrorismo, de risco, fazendo com que o refugiado se assemelhe, assim, à vilões da sociedade, ao invés de alguém a ser integrado como qualquer outro membro.

O quadro normativo internacional, porém, impulsiona a tomada de medidas em visão de uma integração efetiva, como muitas vezes afirmada na própria convenção de 1951 (ONU, 1951), e protegida como um objetivo a ser alcançado. Uma das muitas iniciativas que podem ser tomadas para este fim, é a inserção de refugiados no sistema de educação superior. Não obstante, a retórica usada pela mídia e por políticos que cria uma imagem subjetiva de refugiados, tem repercussões perceptíveis nas universidades, como uma crescente intolerância e inflexibilidade sistêmica universitária, tanto no processo de seleção de vagas quanto durante a graduação (Stevenson et al, 2018).

Nesse sentido, a literatura sobre o acesso à educação, segundo Isil Güney (2017), passou por uma evolução em que diversos significados da educação em nível superior foram pensados, se tornando mais ou menos suscetíveis à adoção de alguma medida de facilitação de ingresso para refugiados, e minorias em geral. Até a década de 1960, o campo foi dominado pelas teorias 
funcionalistas ${ }^{4}$, e mais tarde por aqueles que Güney denomina de teóricos do conflito ${ }^{5}$. Além dessas, Güney (2017) identifica como mais proeminente no campo de estudos sobre educação atualmente, as teorias econômicas, cujo principal objetivo é a avaliação do retorno econômico que a educação superior proporciona. Aqui, se considera que uma participação maior de alunos em instituições de ensino significa um maior crescimento econômico. Por isso, se adota o conceito de "Widening Participation" (WP), um termo que costuma se referir a uma tentativa de aumentar o número de estudantes provenientes de grupos minoritários em universidades, ou seja, aumentar tanto o número quanto a diversidade de estudantes (Güney, 2017).

Esse conceito surgiu a partir de uma clara distinção entre padrões de participação no ensino superior, destacando que jovens de grupos minoritários não tinham uma representação igualitária na faculdade, o que era visto como "injusto" (Evans et al, 2017). Nesse sentido, se visa obter uma perspectiva mais ampliada das possibilidades de acesso à universidades que garantam uma maior participação da população como um todo (Güney, 2017). Não só essa iniciativa visa à uma inclusão de grupos étnicos, sociais e culturais mais amplos, como também pode servir para compreender melhor estudantes mais velhos, ou aqueles que trabalham. A esperança para as instituições e governos que adotam esse principio é que pessoas que não consideravam a educação uma alternativa viável, seja por causa de barreiras institucionais, sociais, culturais ou econômicas, se sintam mais motivadas em se candidatarem para a universidade (Action on Access, 2005).

É importante apontar que tais iniciativas, em geral, tiveram sucesso limitado, não conseguindo adotar medidas que garantam total paridade entre os grupos de estudantes universitários. Stevenson \& Baker (2018), apontam que a mudança se resume recorrentemente ao aumento do numero de mulheres e estudantes mais velhos, porém, raramente se traduz em diversidade socioeconômica. Tal fato, em contrapartida, pode ser explicado pela origem do conceito da Widening Participation em teorias econômicas, o que contribuiria para que a tendência do discurso da WP seja sempre associada à uma justificativa lucrativa, ao invés de justiça social.

\footnotetext{
${ }^{4}$ Os funcionalistas acreditavam que a educação deveria ser tratada como um canal para a modernização de desenvolvimento de uma sociedade, sendo as instituições de ensino um local que proporciona equidade aos cidadãos, baseadas na meritocracia.

${ }^{5}$ Os teóricos do conflito por sua vez, criticavam teorias prévias por serem descoladas da realidade, e assim defenderem uma visão de mundo ideal onde conceitos como a meritocracia são efetivos, quando, na realidade essa funciona como um reforço das desigualdades já existentes. Aqui, se entende que a escola tradicional reproduz condições e identidades sociais que moldam as chances de indivíduos.
} 
Essa limitação pode ser associada ao fato de que esse conceito, não é igualmente adotado por todas as instituições que o defendem. De acordo com Güney (2017), existem 3 tipos de respostas que as instituições podem dar com relação à adoção da WP: a acadêmica, a utilitária, e a transformativa. Dentre as três, as duas primeiras entendem que um baixo número de estudantes se deve às suas competências individuais. Em outras palavras, os potenciais alunos não teriam aspirações ou não teriam capacidades suficientes. Logo, essas iniciativas não objetivam uma mudança institucional, mas sim que os alunos mudem para se conformarem às universidades e, para isso, é dado suporte para que consigam adaptar-se às antigas instituições.

Frequentemente como exemplo do sucesso de tais medidas, são transmitidas histórias individuais, daqueles que de certa forma conseguiram superar as baixas expectativas quanto ao seu sucesso. Essas narrativas podem ser adotadas por universidades que contariam relatos de seus alunos refugiados que conseguiram se inserir no sistema de estudo, e, seja pelas abordagens da WP acadêmica ou utilitária, se conformaram à padrões de ingresso tradicional. Porém, essa perspectiva não compreende as características sistemáticas que impedem o acesso do grupo refugiados ao ensino superior (Stevenson et al, 2018). Aqui, então, há uma falsa sensação de que se um refugiado consegue vencer suas circunstâncias e se formarem na faculdade. Assim, se configura uma situação que não contribui para a implementação de uma mudança estrutural, mas que talvez suporte e justifique as medidas de WP acadêmica e utilitária.

É somente a terceira abordagem, a transformativa, que não se conforma o foco no individuo. As instituições que adotam essa perspectiva, tendem a entender que é a própria universidade que deve se adaptar e se transformar, conseguindo adotar alunos mais diversos. Aqui, portanto, temos uma transformação na própria universidade, o que envolve uma mudança no conteúdo dos cursos, estruturas de organização e no processo de admissões (Güney, 2017). Sendo assim, não se entende, nesse caso, que o motivo pelo qual não existe diversidade no ensino superior reside em problemáticas dos indivíduos, mas que a própria estrutura se mostra intransigente com determinados grupos de pessoas.

De qualquer forma, uma vez que o princípio de WP possui a denotação de ampliar o acesso à educação superior, e prezar por uma abrangência social nesse aspecto, o refugiado, nesse caso, pode ser inseridos em um grupo maior de minorias sociais que seriam abrangidas pelo WP. Ainda assim, para que se consiga ter uma mudança duradoura da situação, é preciso que se implemente uma abordagem transformativa, que justamente olha para a questão de modo estrutural e não individual, e assim consegue atingir o objetivo do acesso a universidade pelo 
grupo de refugiados, ao invés de se restringir a alguns casos individuais. Mais a fundo, se torna importante entender que refugiados, ou migrantes em geral, possuem questões secundárias mais especificas que precisariam ser abordadas por essa mudança transformativa. Nesse tópico, estudos (Stevenson et al., 2007; Güney, 2017; Dryden-Peterson et al., 2010) apontam que além das barreiras mais comuns como as condições de admissão de faculdades, os custos necessários para essa experiência, e características sócio-econômicas, contam também com variáveis como as questões da barreira linguistica, do reconhecimento de estudo prévio, falta de um suporte social, falta de estimulo, receio de discriminação, entre outros.

Logo, se olharmos mais a fundo para a experiência do refugiado durante os seus anos de estudo na faculdade, é importante lembrar que somente a vertente do princípio de WP transformativa, poderá servir de mudança para a melhora da integração acadêmica do refugiado na faculdade. Isto é, além de procurar incentivar e facilitar a entrada de refugiados em universidades, a WP transformativa, possui uma abordagem mais holística, que promove uma reestruturação completa do ensino superior, e que poderia, então, atentar para algumas necessidades de refugiados durante a sua graduação. É importante lembrar, porém, que esse tipo de implementação da WP é apontada por Güney (2017), como a mais rara e a que mais diverge da definição original de WP, associada a teoria da educação econômica.

Ainda assim, se adotada, a WP transformativa poderia produzir algumas transformações na faculdade que procuram facilitar o dia-a-dia do estudante universitário, e do refugiado estudante. É importante atentar para isso, uma vez que a integração do refugiado a sua sociedade hospedeira e ao mercado de trabalho da mesma depende, em grande parte, da conclusão do ensino superior. Nesse sentido, é preciso, assim, assegurar que as taxas de evasão de refugiados do ensino superior sejam baixas, o que pode ser alcançado pelo entendimento da dimensão da integração dentro do espaço da universidade. Diversos estudos já realizados observam a relação entre a performance acadêmica de estudantes e o nível de integração social do mesmo. A integração social seria, de acordo com Rientes (2011), o nível em que os estudantes se adaptam ao modo de vida social universitário.

É uma opinião compartilhada nesse campo que os estudantes bem sucedidos costumam participar tanto na dimensão acadêmica na universidade, quando na cultura universitária. Quanto mais socialmente integrado, mais provável é que o estudante se forme. Há portanto, uma gama de ajustes a serem feitos para possibilitar o sucesso de estudantes. Esses ajustes dizem respeito a processos de integrações pelos quais eles devem passar que, por sua vez, incluem: a acadêmica; a social - que irá se preocupar com as relações interpessoais entre seus 
pares na universidade; a emocional - que irá avaliar o nível de estresse psicológico que essa transição traz; e o comprometimento - que vai refletir o nível de conexão entre o estudante e a universidade (Rientes et al, 2011; Polydoro, 2001)

Se destaca, também, que a integração universitária é um processo extremamente individual e dependerá do bem-estar físico e psicológico do universitário e de sua estabilidade emocional em termos acadêmicos, sociais e pessoais (Polydoro, 2001). Entretanto, fatores externos também irão influenciar na efetividade dessa integração estudantil (Polydoro, 2001). Tanto o ambiente, ou seja, a própria instituição universitária, quanto os demais estudantes, devem conseguir responder às necessidades do indivíduo. Os últimos, inclusive, são especialmente relevantes em casos de estudantes estrangeiros.

No caso de estudantes internacionais, ainda, é preciso considerar outros fatores pessoais, como os choques cultuais, o sentimento da discriminação, ou a saudade da pátria, que aumentam seu nível de estresse e dificultam a integração (Rientes et al, 2011). Assim, além das variáveis apontadas nos estudos anteriores, precisamos agora lembrar que nesse caso, os estudantes internacionais precisam se esforçar mais do que o normal para estabelecer uma integração social, pois toda a sua rede de relações, familiares e sociais, não costumam estar presentes nesse novo ambiente (Rientes et al, 2011). Temos, portanto, um processo relacional entre os indivíduos envolvidos, que irá se debruçar sobra a forma de como essas culturas interagem e como elas se transformam mutuamente, um processo que costuma ser mais agudo quanto mais diferente as culturas em questão são.

Dessa forma, a questão das circunstâncias étnicas entram como um fator decisivo no processo da integração social, e em extensão na integração acadêmica de estrangeiros (Rientes et al, 2011). Uma vez que cada estudante tem uma variedade de experiências prévias educacionais, metodológicas, culturais e familiares que os caracterizam como um certo tipo de aluno. Tanto acadêmica quanto socialmente, isso pode dificultar a sua experiência na universidade, dependendo das diferenças culturais associadas em cada caso.

Nesse ponto, o artigo de Carla Silva, José Luís Abrantes \& Isabel Duarte (2009) pode contribuir para a análise de integração com o uso da Escala de integração social e acadêmico (ISA). A escala é apontada pelo artigo como sendo uma ferramenta que consegue compreender diversas dimensões atribuídas a integração de alunos em faculdades, possuindo três dimensões, cada uma com diversos fatores. As dimensões são a pessoal, a social e a acadêmica, que destacam aspectos psicológicos, econômicos e sociais já mencionados por outros artigos de modo sistematizado, como exposto na tabela 1. Dentre as variáveis apontadas, algumas se 
destacam em especial para casos de estudantes refugiados: o apoio familiar, o domínio da língua, o apoio financeiro, e a tolerância cultural.

Tabela 1: Fatores da Escala de Integração Social e Académica (ISA)

\begin{tabular}{|c|c|c|}
\hline Dimensão pessoal & Dimensão social & Dimensão acadêmica \\
\hline Bem estar físico e psicológico & Relações com professores e colegas & Qualidades das infraestruturas \\
\hline Equilíbrio emocional & Laços de amizade & $\begin{array}{l}\text { Serviço de escola, acolhimento e } \\
\text { receptividade }\end{array}$ \\
\hline autoconfiança & Tolerancia cultural & Programas institucionais de apoio \\
\hline $\begin{array}{l}\text { Apoio familiar } \\
\text { motivação }\end{array}$ & $\begin{array}{l}\text { Bom ambiente academico } \\
\text { Participação extra curricular }\end{array}$ & \\
\hline Domínio da lingua & & \\
\hline Autonomia e independencia & & \\
\hline Apoio financeiro & & \\
\hline
\end{tabular}

Fonte: Silva et al, 2009

Pode-se supor, então, que às condições usuais de integração de alunos acresce-se, algumas dificuldades particulares em casos de alunos refugiados. Por exemplo, a respeito do apoio familiar, em casos de separação no processo de deslocamento. Dessa forma tal refugiado que se insere em um contexto universitário pode não ter consigo uma rede de apoio de seus familiares.

Outra dificuldade adicional para refugiados é a variável domínio da língua. Não é raro casos em que refugiados chegam aos seus países hospedeiros e não sabem falar a língua local, precisando dessa forma, mesmo antes do ingresso a faculdade se familiarizar com a mesma em nível acadêmico. Ainda assim, o processo de aprendizado de uma nova língua, e o costume de se comunicar através dela, no lugar de sua língua materna é um processo demorado e complexo que não costuma ser atingido com facilidade ou na sua completude. Visto assim, podemos supor que a variável que se refere a capacidade linguística de alunos para a sua integração no ensino superior se mostra ainda mais aparente no caso de refugiados. Além disso, vale lembrar que o artigo de Carla Silva (2009), destaca que há uma relação causal entre essa variável linguistica e outra variável importante de integração, que diz respeito ao nível de independência e autonomia do aluno, que é necessária uma vez que a própria transição para o ensino superior implica em um processo de mudança e adaptação a novos papéis e responsabilidades. 
Um terceiro fator é o apoio financeiro. Se destaca no caso de refugiados universitários a necessidade de um apoio financeiro providenciado pela universidade ou o governo, uma vez que normalmente refugiados passem por dificuldades econômicas em seus países hospedeiros devido a dificuldade de se arrumar um emprego de boa remuneração ao chegar em uma nova sociedade.

Ademais, no que se refere aos valores sociais que contribuem para a integração acadêmica, a tolerância cultural se destaca como principal obstáculo entre o refugiado e a sua integração com o ambiente universitário. Nesse sentido, existem fronteiras, especialmente entre os refugiados e a sociedade hospedeira, que podem prejudicar a habilidade do mesmo de interagir com os demais alunos e seus professores, prejudicando assim a sua integração (Naidoo, 2018). Ao mesmo tempo, é possível também que tais fronteiras étnicas se caracterizem como um espaço de contato, de intercâmbio entre dois grupos que interagem apesar de suas diferenças. O impacto dessas diferenças nas relações entre os grupos, porém, dependerá, entre outros fatores, do caráter dos dois grupos envolvidos - isto é, da disposição para a cooperação entre si para que se assegure uma convivência funcional, de modo que esta é uma provisão determinada somente de caso em caso (Rientes et al, 2011). Aqui se destaca a importância da criação de iniciativas pelas comunidades locais que assistam esse procedimento de ingresso. Por exemplo, professores que se empenhem pessoalmente com refugiados, faz completa diferença no sentimento de capacidade de inserção dos refugiados na universidade (Naidoo, 2018).

Portanto, pode-se observar que ao passo que a integração social na universidade é essencial para que não se tenha um fenômeno crônico de evasão do ensino e que refugiados, são um grupo que enfrentam dificuldades adicionais específicas, é preciso que se considere tais obstáculos frente ao acesso de refugiados a um diploma universitário. Caso não sejam observados, é possível que se crie um ambiente de desmotivação para os refugiados perseguirem uma graduação. De qualquer forma, como anteriormente aludido, quatro variáveis se destacam no processo de assegurar uma integração efetiva dos refugiados às universidades: o apoio financeiro, o domínio da língua, o apoio familiar e a tolerância cultural.

\section{Medidas observadas no Brasil}

Segundo o relatório sobre o perfil socioeconômico dos refugiados no Brasil, produzido pela ACNUR em 2019, em média o nível de escolaridade de refugiados é maior do que o de brasileiros. Ainda assim, somente $34,4 \%$ haviam concluído o ensino superior (ACNUR Brasil, 
2019), e considerando também que quase $33 \%$ de todos os refugiados no Brasil tem entre 18 e 29 anos (Ministério da Justiça e da Segurança Pública, 2018), há portanto, um número considerável de refugiados que podem estar interessados em ingressar na universidade. Foi ainda apontado diretamente pelo relatório que uma grande maioria dos refugiados abordados pela pesquisa demonstraram interesse em continuar os seus ensinos, mostrando que dentro da amostra, $78 \%$ desejavam continuar seus estudos, porém, desses, somente $8 \%$ se declararam estudantes (ACNUR Brasil, 2019).

Outro dado interessante apontado pelo relatório chama atenção ao fato de que entre refugiados é extremamente comum estar desempregado, ou trabalhando fora de sua área de especialidade, o que faz com que a saída mais comum encontrada por eles seja investir no empreendedorismo. Ainda assim, a renda mensal de um refugiado no Brasil atualmente, é de 3000 reais (ACNUR Brasil, 2019). Sendo assim, o êxito em obter um diploma de uma graduação no Brasil, pode melhorar as chances de refugiados de se integrarem no mercado de trabalho formal nacional.

Como ator no campo da educação superior no Brasil para refugiados, se destaca a Cátedra Sérgio Vieira de Mello. A Cátedra é um projeto da ACNUR de 2003, que tem como objetivo primordial expandir o conhecimento sobre o conhecimento acadêmico na área de refúgio na América Latina, mas que com os anos expandiu seu âmbito para a prestação de serviços aos refugiados. Com essa mudança de rumo, o projeto foi relançado em 2010 com uma organização em três pilares: ensino, pesquisa e extensão. Enquanto as duas primeiras se concentram com a oferta de cursos sobre refúgio e a publicação acadêmica sobre o assunto, a vertente da extensão incentiva universidades a abrir vagas para refugiados (Moreira, 2015). O programa pode ser implementado por iniciativa autônoma de universidades no Brasil, que podem escolher adotá-lo completo, ou parcialmente. Atualmente, 13 universidades brasileiras ${ }^{6}$ adotam o programa da cátedra no eixo da extensão, promovendo o ingresso facilitado para refugiados com o oferecimento de 225 vagas para refugiados no ano de 2019 (ACNUR Brasil, 2019). Essas universidades, ao implementarem o programa, adotam algumas das 6 medidas propostas pela organização, como a criação de um processo seletivo específico, a concessão de

\footnotetext{
${ }^{6}$ Universidade Católica de Santos (Unisantos); Universidade de Brasília (UnB); Universidade de Vila Velha (UVV-ES); Universidade Estadual de Campinas (UNICAMP); Universidade Federal de Roraima (UFRR); Universidade Federal de Santa Maria (UFSM); Universidade Federal do ABC (UFABC); Universidade Federal do Espírito Santo (UFES); Universidade Federal do Paraná(UFPR) ; Universidade Federal do Rio Grande do Sul (UFRGS); Universidade Federal Fluminense (UFF); Universidade Federal de São Paulo (UNIFESP); Universidade Federal de São Carlos (UFSCar) (ACNUR Brasil, 2019)
} 
bolsas de estudo, a assistência na revalidação de diplomas de graduação ou pós-graduação, programas de assistência social, entre outros.

Quanto à questão da assistência ao refugiado durante seu período no ensino superior, pode-se verificar que a CSVM promove certas ações que contribuem para a mesma, facilitando a sua adaptação quanto a três das quatro variáveis destacadas acima: o apoio financeiro, o domínio da língua e o apoio familiar.

No âmbito do apoio financeiro, além de assegurar que bolsas sejam dadas a refugiados no seu ingresso a faculdade, os aliviando da taxa de mensalidade em universidades privadas (ACNUR Brasil, 2018), a CSVM também promove outras iniciativas, como um apoio monetário. Dentre elas se destacam serviços de saúde e assessoria jurídica. A CSVM então, incentiva que universidades vinculadas se engajem em garantir o acesso a serviços de saúde essenciais, permitindo por exemplo, o acesso ao hospital da clinica dos departamentos de saúde das faculdades, assim como a promoção de aulas de capacitação e sensibilização de profissionais da área de saúde sobre o assunto (ACNUR Brasil, 2018). Em 2019, 12 faculdades ${ }^{7}$

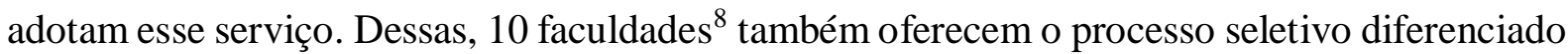
para refugiados (ACNUR Brasil, 2019), de forma que os refugiados que são alunos pela iniciativa da CSVM em Brasilia não têm acesso a tais serviços de saúde. Além disso, quanto ao serviço de assessoria jurídica, a CSVM entende que as universidades a ela vinculadas devem se envolver na promoção da proteção jurídica dos mesmos, garantindo o acesso a justiça, de forma economicamente acessível (ACNUR Brasil, 2018). Essa iniciativa conta com a adoção

\footnotetext{
${ }^{7}$ Pontifícia Universidade Católica do Rio de Janeiro (PUC-Rio); Universidade Estadual do Rio de Janeiro (UERJ); Universidade Federal do Espírito Santo (UFES); Universidade Federal de São Carlos (UFSCAR); Universidade Federal Roraima (UFRR); Universidade de Campinas (UNICAMP); Universidade Federal do Estado de São Paulo (UNIFESP); Universidade de Vila Velha (UVV-ES); Universidade Federal de Santa Maria (UFSM); Universidade Católica de Santos (UNISANTOS); Universidade Federal Fluminense (UFF); Universidade Federal do Paraná (UFPR).

${ }^{8}$ Universidade Federal do Espírito Santo (UFES); Universidade Federal de São Carlos (UFSCAR); Universidade Federal Roraima (UFRR); Universidade de Campinas (UNICAMP); Universidade Federal do Estado de São Paulo (UNIFESP); Universidade de Vila Velha (UVV-ES); Universidade Federal de Santa Maria (UFSM); Universidade Católica de Santos (UNISANTOS); Universidade Federal Fluminense (UFF); Universidade Federal do Paraná (UFPR).
} 
de 14 universidades brasileiras ${ }^{9}$, das quais, $8^{10}$ tem vagas reservadas para refugiados (ACNUR Brasil, 2019), isso significa que, novamente, aqueles refugiados da universidade conveniada à CSVM em Brasilia, não têm acesso a esse serviço.

Além do apoio monetário, a CSVM também ajuda refugiados no aprendizado da língua portuguesa. Nesse sentido, são 18 universidades ${ }^{11}$ que se disponibilizam a oferecer aulas gratuitas de português (ACNUR Brasil, 2019), sendo esta a iniciativa mais difundida da Cátedra, não deixando nenhum Estado sem tal oportunidade.

Por fim, quanto ao apoio familiar, para aqueles refugiados que se encontram sozinhos, uma medida adotada pela Cátedra que pode contribuir para a melhoria da situação do refugiado é um apoio de saúde mental e psicossocial. Assim, a CSVM busca garantir o bem-estar psicológico de refugiados com a associação a departamentos de psicologia de universidades, que oferecem o apoio psicológico aos refugiados. Atualmente, são 11 universidades $^{12}$ que adotam a iniciativa (ACNUR Brasil, 2019), ficando de fora os Estados de Brasília e Roraima que não tem tal extensão do programa da Cátedra.

Quanto à variável a tolerância cultural, não há iniciativa da cátedra que lide diretamente com tal fator. Porém, ao promover um eixo que incentiva a elaboração de grupos de pesquisa voltados à investigação do tema de refúgio, financiando pesquisas a serem publicadas, a oferta de cursos sobre o mesmo (ACNUR Brasil, 2018), a Cátedra de certa forma também expande o

\footnotetext{
${ }^{9}$ Fundação Casa de Rui Barbosa (FCRB); Pontifícia Universidade Católica do Rio de Janeiro (PUC-Rio); Universidade Federal da Paraíba (UEPB); Universidade Federal do Espírito Santo (UFES); Universidade Federal da Grande Dourados (UFGD); Universidade Federal do Paraná (UFPR); Universidade Federal de Santa Catarina (UFSC); Universidade Federal do Rio Grande do Sul (UFRGS); Universidade Federal de Roraima (UFRR); Universidade Federal de Santa Maria (UFSM); Universidade de Vila Velha (UVV-ES); Universidade Católica de Santos (UNISANTOS); Universidade Federal Fluminense (UFF); Pontifícia Universidade Católica de São Paulo (PUC-SP).

${ }^{10}$ Universidade Federal do Espírito Santo (UFES); Universidade Federal do Paraná (UFPR); Universidade Federal do Rio Grande do Sul (UFRGS); Universidade Federal de Roraima (UFRR); Universidade Federal de Santa Maria (UFSM); Universidade de Vila Velha (UVV-ES); Universidade Católica de Santos (UNISANTOS); Universidade Federal Fluminense (UFF).

${ }^{11}$ Pontifícia Universidade Católica do Rio de Janeiro (PUC-Rio); Universidade Estadual da Paraíba (UEPB); Universidade Estadual do Rio de Janeiro (UERJ); Universidade Federal do ABC (UFABC); Universidade Federal do Espírito de Santo (UFES); Universidade Federal da Grande Dourados (UFGD); Universidade Federal do Paraná (UFPR); Universidade Federal de Roraima (UFRR); Universidade Federal de Santa Catarina (UFSC); Universidade Federal de São Carlos (UFSCAR); Universidade Federal de Santa Maria (UFSM); Universidade de Brasília (UnB); Universidade de Campinas (UNICAMP); Universidade Federal do Estado de São Paulo (UNIFESP); Universidade de Vila Velha (UVV-ES); Universidade Federal Fluminense (UFF); Pontifícia Universidade Católica de São Paulo (PUC-SP); Universidade Federal do Rio Grande do Sul (UFRGRS).

${ }^{12}$ Pontifícia Universidade Católica do Rio de Janeiro (PUC-Rio); Universidade Estadual do Rio de Janeiro (UERJ);Universidade Federal do Paraná (UFPR); Universidade Federal de Santa Catarina (UFSC); Universidade Federal do Rio Grande do Sul (UFRGS); Universidade de Campinas (UNICAMP); Universidade Federal do Estado de São Paulo (UNIFESP); Universidade de Vila Velha (UVV-ES); Pontifícia Universidade Católica de São Paulo (PUC-SP); Universidade Federal Fluminense (UFF); Universidade Católica de Santos (UNISANTOS).
} 
conhecimento sobre o tema e, assim, promove uma maior conscientização tanto para alunos universitários quanto para professores, o que pode contribuir para a melhoria da tolerância cultural.

Quanto a este tópico ainda é importante lembrar que, como apontado por Ola Mostafa (2017), a integração é um processo bilateral, no sentido em que tanto a população nacional quanto a população refugiada devem agir ativamente para promover uma harmonia de grupo. Sendo assim, é necessário que se veja um trabalho em conjunto.

Nesse sentido, é quase consenso entre a população de refugiados no Brasil, como apontado pelo relatório socioeconômico da ACNUR (2019), o desejo de ser parte integrante ativa da sociedade brasileira. Nesse sentido, 96,3\% dos entrevistados demonstraram interesse em se tornarem cidadãos brasileiros; 80,6\% desejavam votar (ACNUR Brasil, 2019). Sendo assim, é perceptível que há grande engajamento por parte de refugiados em se tornarem parte da comunidade nacional.

Por outro lado, o relatório também aponta certas barreiras institucionais que refugiados enfrentam em seu dia-a-dia no Brasil. Especificamente na área educacional, é baixa a taxa de refugiados que conseguem obter uma revalidação de diploma (3\%) (ACNUR Brasil, 2019). O relatório de 2019 da ACNUR Brasil indica também certas barreiras resultantes de interações com a população brasileira. O fator "ser estrangeiro" foi repetidamente referenciado pelos refugiados no relatório como uma dificuldade para o sucesso em tentativas de empreendedorismo, bem como motivo de preconceito, que cerca de $41 \%$ dos entrevistados admitiram ter sofrido (ACNUR Brasil, 2019). Outras tendências conflitantes são apontadas: ao passo que $91 \%$ dos refugiados apontados no relatório consideram que tem amigos brasileiros, somente $28,5 \%$ participam de alguma associação oficial, e 23,4\% admitiu participar de atividades sociais somente dentro de seu círculo nacional (ACNUR Brasil, 2019). Se configura então, um quadro em que "há ainda muito caminho a percorrer em termos de integração para parte significativa dos refugiados hoje instalados no Brasil” (ACNUR Brasil, 2019, p. 14).

No âmbito do papel das faculdades, é possível verificar que em todas as universidades com vagas para refugiados há a promoção, como mencionado anteriormente, de eventos acadêmicos e aulas sobre o tema de refúgio, organizados muitas vezes pela própria CSVM. Por outro lado, pesquisas em sites de tais universidades mostram que são poucas as alternativas de 
eventos culturais. Dentre as 11 universidades com vagas para refugiados, somente $4^{13}$ universidades registraram em seus sites que promoveriam um evento em celebração ao dia do refugiado, enquanto somente 1 universidade, a Unisantos, tem em seu site uma campanha para a promoção de apadrinhamentos de refugiados (Universidade Católica de Santos, 2019). Além disso, somente 1 universidade, a Universidade Federal do Paraná, registrou em seu site a promoção de outros eventos culturais que visavam essa interação, como uma exposição de painéis com histórias de refugiados (Universidade Federal do Paraná, 2019b; Universidade Federal do Paraná, 2019c) Assim sendo, somente 5 universidades das 11 que oferecem vagas para refugiados promovem eventos culturais de interação entre refugiados e os demais estudantes, segundo os eventos que estão registrados em seus sites oficiais. Portanto, nota-se que em grande maioria, são eventos estritamente acadêmicos que, embora visem a expansão da consciência sobre o tema do refúgio, não estimulam uma interação mais pessoal entre brasileiros e refugiados.

Os dados coletados se encontram sintetizados na tabela 2 abaixo e mostram que, apesar das medidas que tem como objetivo a promoção da integração acadêmica do refugiado, poucas podem ser consideradas completas. A CSVM, como o principal ator identificado promove o acesso amplo tanto da bolsa acadêmica quanto do apoio linguístico aos refugiados que tem ocupam vagas em universidades. Entretanto, quanto as outras medidas, é possível identificar Estados que não se mostram capazes de prover o serviço aconselhado pela cátedra, com destaque ao Estado de Brasília, que se apresenta como o Estado com menor adoção de iniciativas da CSVM. Entretanto, é importante notar que a iniciativa da CSVM se encontra em processo de expansão, uma vez que enquanto que em 2018 eram 11 universidades que ofereciam vagas para refugiados, em 2019 a CSVM já conta com 13 universidades que aderiram às medidas (ACNUR Brasil, 2019). Nesse período, todas as outras iniciativas aqui citadas também foram expandidas significativamente. Logo, é possível afirmar que tanto mais refugiados tem acesso a vagas universitárias quanto refugiados já universitários tem acesso à tais serviços complementares promovidos pela CSVM.

Por fim, quanto a variável da tolerância cultural, que não se encontra como uma medida promovida pela CSVM, é possível perceber que esta representa a iniciativa menos avançada das que foram citadas. Consequentemente, é pequeno o número de Estados com medidas nesse

\footnotetext{
${ }^{13}$ Fundação Casa de Ruy Barbosa; Universidade Estadual de Campinas (UNICAMP); Universidade Federal do ABC (UFABC); Universidade Federal do Paraná (UFPR) (Universidade Federal do Paraná, 2019a; Unicamp, 2019; Universidade federal do ABC, 2019; ONU Brasil, 2019).
} 
sentido. Tal fato mostra tanto uma falta de iniciativa independente das universidades brasileiras, quanto uma deficiência na promoção de um bom recebimento dos refugiados por parte das pessoas na universidades, sejam outros alunos ou professores.

\section{Tabela 2: Relação dos dados coletados}

\begin{tabular}{|c|c|c|}
\hline Iniciativa CSVM & $\begin{array}{c}\text { Número de faculdades que adotam } \\
\text { medidas propostas }\end{array}$ & $\begin{array}{c}\text { Estados com alunos refugiados } \\
\text { que não possuem acesso às } \\
\text { iniciativas }\end{array}$ \\
\hline Apoio Financeiro: Bolsa acadêmica & 13 & Nenhum \\
\hline Apoio Financeiro: Serviços de saúde & 12 & 1 \\
\hline Apoio Financeiro: Serviços jurídicos & 14 & 1 \\
\hline Apoio Linguístico & 18 & Nenhum \\
\hline Apoio familiar & 11 & 2 \\
\hline $\begin{array}{l}\text { Iniciativa de universidades }{ }^{14} \text { : } \\
\text { Tolerância cultural }\end{array}$ & 5 & 4 \\
\hline
\end{tabular}

Fonte: Dados obtidos de ACNUR Brasil, 2019; Universidade Católica de Santos, 2019; Universidade Federal do Paraná, 2019a; Unicamp, 2019; Universidade federal do ABC, 2019; ONU Brasil, 2019; Universidade Federal do Paraná, 2019b; Universidade Federal do Paraná, 2019c.

\section{Considerações finais}

É preciso chamar atenção para o quadro em que o Brasil se encontra no que diz respeito ao recebimento em massa e crescente de refugiados. Recebendo milhares de refugiados por ano, o Brasil se torna responsável pelo acolhimento e bom tratamento dessas pessoas. Sendo assim, é preciso que se promova ativamente práticas de bom acolhimento para refugiados e de integração ativa dos mesmos na sociedade brasileira.

De acordo com o relatório socioeconômico dos refugiados no Brasil da ACNUR (2019), uma vasta maioria dos refugiados desejam fazer parte de uma comunidade brasileira, porém,

\footnotetext{
${ }^{14}$ Uma vez que não há iniciativa concreta da CSVM, a variável foi analisada pelas iniciativas autônomas das universidades, por meio de pesquisas em seus sites oficiais.
} 
na prática, tal desejo não tem encontrado ressonância nas medidas implementadas . No campo da educação superior, por exemplo, apesar de grande parte dos refugiados no Brasil expressarem um desejo de continuarem seus estudos (ACNUR, 2019), temos somente um único programa, da Cátedra Sérgio Vieira de Mello (CSVM), que promove a criação de vagas especificamente para refugiados em universidades brasileiras. Portanto, apesar de haver esforços para facilitar a entrada de refugiados ao ensino superior no Brasil, esse ingresso ainda não se mostra amplamente capilarizado nas universidades brasileiras. Entretanto, a CSVM, como iniciativa vem crescendo bastante: em 2018, existiam um total de 374 vagas para refugiados em de 11 universidades brasileiras (ACNUR Brasil, 2018) enquanto em 2019, existem 225 vagas para refugiados em 13 universidades (ACNUR Brasil, 2019).

Mais a fundo, se mostrou necessário atentar para as próprias condições e demandas de refugiados que se tornam estudantes universitários, afim de se promover o ingresso de refugiados na universidade de forma segura e visando melhorias nas suas qualidades de vida, de se inserirem no mercado de trabalho, e de se integrarem. Dessa forma, é preciso olhar para as condições presentes nas sociedades para que refugiados consigam ter sucesso acadêmico mediante a obtenção do diploma de graduação .

Nesse sentido, as abordagens teóricas constantemente apontam que uma boa experiência educacional para estudantes universitários é dependente do nível de integração social dos mesmos nesse novo ambiente. Mais especificamente, o sucesso acadêmico está associado a uma integração acadêmica, social, pessoal e ao nível de comprometimento do estudante com seu curso. Se destaca, ademais, que esse processo é algo extremamente individual, já que depende também do estado mental de cada individuo e também uma variável externa, a recepção do ambiente, relevante.

Assim, ainda que o aspecto pessoal de cada estudante seja primordial para assegurar a sua integração efetiva em universidades, o acolhimento do ambiente também é imprescindível. Essa afirmação aponta que é preciso que as universidades ofereçam as condições que viabilizam a integração, respondendo, assim, às necessidades interativas de estudantes. Na prática, essas condições nem sempre são oferecidas, uma vez que a compreensão das mesmas por parte da universidade podem não ser suficientes. Por isso, existe a abordagem do conceito de WP transformativa que visa à uma mudança institucional de universidades para que se consiga absorver alunos mais diversos como integrantes desse espaço.

Essa adoção transformativa é uma de três maneiras que a WP pode ser implementada, e a única que identifica a solução para o aumento da diversidade na universidade na estrutura e 
não no próprio estudante. Ao passo que essa abordagem transformativa é a menos provável de ser adotadas na atualidade, fica menos provável que haja a promoção real de uma mudança socioeconômica do perfil de estudantes universitários. Não obstante, a implementação de tal medida poderia ajudar a compreender melhor as necessidades que os estudantes enfrentam para que consigam se integrar ao ensino superior efetivamente.

Dentre as diversas variáveis para a integração social, acadêmica e pessoal do estudante, há outras que se destacam como especialmente problemáticas no que diz respeito aos casos de estudantes refugiados. Fatores como a falta de apoio familiar e financeiro, a dificuldade frente ao domínio da língua e uma intolerância cultural são fatores que recorrentemente aparecem frente ao sucesso do refugiado em sua trajetória na universidade e, assim, podem dificultar e até impedir que ele se forme.

No Brasil, podemos apontar como ator principal da promoção dessa integração e uma via facilitadora no atendimento das necessidades intrínsecas a esse processo, a Cátedra Sérgio Vieira de Mello. Com programas de bolsas acadêmicas, assessoria jurídica, apoio a saúde, apoio psicológico e o oferecimento de aulas de português, a cátedra dá conta de três das quatro variáveis apontadas como críticas nos casos de refugiados. Quanto à ultima variável, nível de tolerância cultural com os refugiados, não há uma iniciativa específica da CSVM, ainda que os eventos acadêmicos de discussão sobre refúgio possam trazer uma maior conscientização de alunos e professores. Além disso, é possível notar que algumas universidades promovem autonomamente eventos culturais que tem como objetivo a promoção de alguma interação social entre refugiados e os demais alunos e professores nas instalações das instituições.

No entanto, mesmo com as iniciativas acima registradas, é importante ressaltar que não há um atendimento completo das necessidades de refugiados. Ainda que os programas incentivados pela CSVM sejam expressivos, eles não são igualmente adotados pelas universidades com vagas para refugiados, de forma que há sempre alguma universidade que não adota alguma das iniciativas citadas, com exceção das aulas de português. Porém, é importante notar que a principal barreira frente essa integração é justamente aquela que apresenta o menor numero de iniciativas: a promoção de eventos acadêmicos. Eles podem servir como meio para estimular a tolerância e poderiam contar com outros tipos de eventos culturais e sociais que com potencial de promover uma interação mais pessoal entre o refugiado e os demais integrantes do ensino superior.

Ainda que haja diversas medidas adotadas no contexto brasileiro para uma assistência aos refugiados frente a essas barreiras, elas são primordialmente adotadas por um só ator, a 
CSVM, que não consegue unilateralmente implementar todas as suas propostas de maneira igualitária e completa entre todas as universidades a ela filiadas. Ao mesmo tempo, as iniciativas adotadas pelas próprias universidades se mostram limitadas para o alcance da meta de diminuição das barreira que esses fatores impõe em frente a integração. Portanto, é possível observar que, no Brasil, as medidas cujo objetivo é garantir a integração acadêmica do refugiado em universidades, embora sejam reconhecidamente importantes, são ainda insuficientes e mostram que ainda existe um caminho a ser percorrido para assegurar a integração da população refugiada

\section{Referências bibliográficas}

\section{ALTO COMISSIARIADO DAS NAÇÕES UNIDAS PARA REFÚGIO [ACNUR]. Turn}

The Tide: Refugee Education in Crisis. Genebra: ONU, 2018.

ACNUR Brasil. Cátedra Sérgio Vieira de Mello: Relatório de atividades, 2018.

Disponível em: <http://www.acnur.org/portugues/wp-content/uploads/2018/09/Relatório-

Cátedra-Sérgio-Vieira-de-Mello-2018_final.pdf>. Acessado em: 17 set. 2018.

_. Termo de referência da cátedra Sérgio vieira de Mello, 2016. Disponível em:

<Termo_de_Referência_CSVM_2016.pdf>. Acessado em: 17 set. 2018.

_. Perfil socioeconômico dos refugiados no Brasil: Subsídios para elaboração de políticas. Disponível em: <https://www.acnur.org/portugues/wp-content/uploads/2019/05/Resumo-Executivo-Versão-Online.pdf>. Acessado em: 11 jun. 2019.

Relatório Anual da Cátedra Sérgio Vieira de Mello: 2019. Disponível em:

<https://www.acnur.org/portugues/wp-content/uploads/2019/09/Relatorio-Anual-

CSVM_Digital.pdf>. Acesso em: 25 de outubro de 2019.

AZEVEDO, Amanda Moraes; DANTAS, Ana Carolina Pinto. Inadequate Integration of Refugees in Brazil as a Violation to the Right of Human Dignity. Revista do CEPEJ, Salvador, V. 20, 2017.

CHUEIRI, Vera Karam de; CÂMARA, Heloisa Fernandes. Direitos humanos em movimento: migração, refúgio, saudade e hospitalidade. Direito, Estado e Sociedade. São Paulo, n.36, 2010 .

DRYDEN-PETERSON, Sarah. The Politics of Higher Education for Refugees in a Global Movement for Primary Education. Refuge: Canada's Journal on Refugees, Toronto, v. 21, n. 2, 2010.

EVANS, Ceryn; REES, Gareth; TAYLOR, Chris; WRIGHT, Caroline. 'Widening Access' to higher education: the reproduction of university hierarchies through policy enactment. Journal of Education Policy, 2017. 
GÜNEY, Isil. Widening Access to Refugees: Responses of Austrian Public Universities. 2017. 96p. Dissertação (Mestrado em Research and Innovation in Higher Education) - Danube University, Krems.

KUHLMAN, Tom. The Economic Integration of Refugees in Developing Countries: A Research Model. Journal of Refugee Studies. Oxford, v. 4, n. 1, 1991.

MINISTÉRIO DA JUSTIÇA E DA SEGURANÇA PÚBLICA [BRASIL]. Refúgio em números. Brasília, 2017. Disponível em: <http://www.acnur.org/portugues/wp-content/uploads/2018/01/refúgio-em-numeros-2010-2016.pdf> Acessado em: 25 jul. 2019.

MOREIRA, Julia Bertino. O Papel das Cátedras Sérgio Vieira de Mello no processo de integração Local dos Refugiados no Brasil. Monções: Revista de Relações Internacionais da UFGD, v.4, n.8, 2015, p.81-96.

. Refugiados no Brasil: Reflexões acerca do processo de integração local. REMHU - Revista Interdisciplinar de Mobilidade Humana. Brasília, ano XXII, n. 43, 2014, p.85-98.

Política em Relação aos Refugiados no Brasil (1947-2010). 2012. 351 p. Tese

(Doutorado em Ciência Política) - Universidade Estadual de Campinas, Instituto de Filosofia e Ciências Humanas, Campinas

MOSTAFA, Ola. Integration of Refugees in Austrian Universities. 2017. 87p. Dissertação Mestrado em Research and Innovation in Higher Education) - Danube University, Krems.

NAIDOO, Loshini; WILKINGSON, Jane; ADONIOU, Misty; LANGAT, Kiprono. Refugee Barckgroung Students Trasitionins Into Higher Education: Navigating Complex Spaces. Singapura: Springer, 2018.

ORGANIZAÇÃO DAS NAÇÕES UNIDAS [ONU] Convenção Relativa ao Estatuto dos Refugiados. Genebra: ONU, 1951.

ONU Brasil. Dia Mundial do Refugiado celebra integração, promove cultura e debate os desafios do refúgio no Brasil. Disponível em: <https://nacoesunidas.org/dia-mundial-dorefugiado-celebra-integracao-promove-cultura-e-debate-os-desafios-do-refugio-no-brasil/> . Acessado em: 11 de junho de 2019

POLYDORO, Suely; PRIMI, Ricardo, SERPA, Maria de Nazaré da F.; ZARONI, Margarida M. Hoeppner; POMBAL, Kelly Cristina Pereira. Desenvolvimento de uma Escala de Integração ao Ensino Superior. Psico-USF, v.6, n.1, jan./jun. 2001, p.11-17.

RIENTES, Bart; BEAUSAERT, Simon; GROHNERT, Therese; NIEMANTSVERDRIEY, Susan; KOMMERS, Piet. Understanding academic performance of international students: the role of ethnicity, academic and social integration. Singapura: Springer, 2011.

SILVA, Carla; ABRANTES, José Luis; DUARTE, Isabel. Integração Social e acadêmica dos alunos provenientes dos PALOP no Ensino Superior Português: Um Estudo de caso. Cabo Verde Redes e Desenvolvimento Regional, Cabo Verde, 2009. 
STEVENSON, Jacqueline; BAKER, Sally. Refugees in Higher Education: Debate, Discourse and Practice. Emerald Publishing Limited, Bingley, 2018

UNICAMP. Dia Mundial do Refugiado será comemorado com atividades na Praça da Paz. Disponível em: <https://www.unicamp.br/unicamp/eventos/2019/06/11/dia-mundial-dorefugiado-sera-comemorado-com-atividades-na-praca-da-paz $>$. Acessado em: 11 de junho de 2019.

\section{UNIVERSIDADE CATÓLICA DE SANTOS. Programa campanha da fraternidade:}

Políticas públicas - refugiados. Disponível em:

$<$ https://www.unisantos.br/portal/acontece/programa-campanha-da-fraternidade-politicaspublicas-refugiados/>. Acessado em: 11 de junho de 2019.

UNIVERSIDADE FEDERAL DO ABC. Dia Mundial do Refugiado. UFABC Eventos, s.d. Disponível em: <http://cecs.ufabc.edu.br/index.php/eventos/394-dia-mundial-dorefugiado.html >. Acesso em: 11 de junho de 2019.

UNIVERSIDADE FEDERAL DO PARANÁ. Evento protagonizado por estudantes da UFPR celebra o Dia Mundial do Refugiado e a Semana do Migrante. UFPR Notícias, s.d.. Disponível em: <https://www.ufpr.br/portalufpr/eventos/evento-protagonizado-porestudantes-da-ufpr-celebra-o-dia-mundial-do-refugiado-e-a-semana-do-migrante/>. Acessado em: 11 de junho de 2019.

. Exposição de painéis com histórias de refugiados será lançada dia 19 no Campus Rebouças. UFPR Notícias, s.d.. Disponível em: $<$ https://www.ufpr.br/portalufpr/noticias/paineis-com-historias-de-refugiados-sera-lancadadia-19-no-campus-reboucas/>. Acesso em: 11 de junho de 2019.

Festa de encerramento de projeto voltado para migrantes e refugiados acontece neste sábado - 9 de dezembro. UFPR Notícias, s.d.. Disponível em: $<$ https://www.ufpr.br/portalufpr/eventos/festa-de-encerramento-de-projeto-voltado-paramigrantes-e-refugiados-acontece-neste-sabado-9-de-dezembro/>. Acesso em: 11 de junho de 2019 